\title{
MARKET SHARE DE EMPRESAS DOMÉSTICAS \\ NA CADEIA PRODUTIVA DA CARNE BOVINA NO BRASIL
}

Market share hold by domestic companies in the beef supply chain in Brazil

DOI: 10.48075/igepec.v25i1.25709

Gabriel da Silva Medina 


\title{
MARKET SHARE DE EMPRESAS DOMÉSTICAS NA CADEIA PRODUTIVA DA CARNE BOVINA NO BRASIL
}

\author{
Market share hold by domestic companies in the beef supply chain in Brazil
}

DOI: 10.48075/igepec.v25i1.25709

Gabriel da Silva Medina

\begin{abstract}
Resumo: A expansão do agronegócio cria oportunidades para investimentos domésticos em diferentes segmentos das cadeias produtivas. Neste trabalho, objetiva-se identificar a participação de grupos brasileiros nos principais segmentos de produção de carne bovina no Brasil. Busca-se identificar oportunidades para investimentos que melhor remunerem capital e trabalho como alternativa à expansão para novas fronteiras agrícolas. $\mathrm{O}$ trabalho foi realizado com base em pesquisa documental dos materiais institucionais das associações setoriais e das empresas que atuam no setor. $O$ estudo revela que $65,6 \%$ da cadeia produtiva da carne são controlados por grupos brasileiros. A participação doméstica se destaca nos segmentos de frigoríficos (com 75,7\% de market share), de produção em campo (99,3\%), de equipamentos (100\%) e de sementes para pasto (95,0\%). O aumento do market share de grupos domésticos nos segmentos agroindustriais que melhor remuneram é uma alternativa para superar a expansão para novas fronteiras agrícolas com altos custos sociais e ambientais.
\end{abstract}

Palavras-Chave: Agronegócio. Indústria nacional. Agroindústria. Agropecuária. Desenvolvimento regional.

\begin{abstract}
Agribusiness growth creates opportunities for domestic investments in different segments of the supply chains. This study seeks to reveal the market share hold by domestic companies in key sectors of Brazil's beef supply chain. It aims to identify opportunities for investments that better remunerate capital and labor as an alternative to expanding the farming sector into new agricultural frontiers. The study was carried out based on institutional materials published by both the sectorial associations and the companies that operate in the sector. The study reveals that $65.6 \%$ of the Brazilian beef supply chain is controlled by domestic groups. Domestic companies' market share stands out in business sectors such as meat processing (with $75.7 \%$ of domestic market share), farming production (99.3\%), equipment (100\%), and seeds for pasture (95.0\%). Growth of domestic market share in agroindustrial segments can boost local economic development, while avoiding farming expansion into new agricultural frontiers with high social and environmental costs.
\end{abstract}

Key words: Brazil. Agribusiness. National industry. Agroindustry. Agriculture. Regional development.

Resumen: El crecimiento del agronegócio crea oportunidades para inversiones domesticas en diferentes segmentos de las cadenas productivas. El objetivo de este estudio es identificar la participación del capital brasileño en los principales segmentos de la cadena productiva de la carne vacuna producida en Brasil. Buscase identificar oportunidades de inversión que remuneren mejor el capital y la mano de obra como alternativa a la expansión hacia nuevas fronteras agrícolas. La investigación se ha llevado a cabo a partir de los materiales institucionales de las asociaciones sectoriales y de las empresas que operan en el sector. El estudio revela que el 65,6\% de la cadena de producción de carne está controlada por grupos brasileños. Se destaca la participación nacional en los mataderos (con 75,7\% de participación de mercado), en la producción de campo (99,3\%), en la manactura de equipamientos (10o\%) y en la producción de semillas de pastos $(95,0 \%)$. El incremento de la participación de mercado de los grupos domésticos en los segmentos agroindustriales que mejor remuneran es una alternativa para superar la expansión hacia a nuevas fronteras agrícolas con altos costos sociales y ambientales.

Palabras clave: Agronegócio, Industria nacional. Agroindustria. Agricultura. Desarrollo regional.

Informe GEPEC, ISSN:1679-415X, Toledo, v. 25, n.1, p.220-239, jan./jun. 2021. 
Informe GEPEC, ISSN:1679-415X, Toledo, v. 25, n.1, p.220-239, jan./jun. 2021. 


\section{INTRODUÇÃO}

O agronegócio é um dos setores econômicos mais dinâmicos no Brasil, levando a debates sobre como seu crescimento pode oportunizar o desenvolvimento regional (OLIVEIRA; RODRIGUES, 2020). Com a perda relativa da participação industrial na economia, o agronegócio tornou-se um dos principais dinamizadores da economia brasileira, inclusive da indústria relacionada à produção agropecuária, e um setor fundamental para a balança comercial do país (NASSIF; BRESSER-PEREIRA; FEIJO, 2017). Em 2019, o agronegócio como um todo, incluindo segmentos à montante e à jusante da fazenda, foi responsável por $21 \%$ do Produto Interno Bruto (PIB) brasileiro, enquanto o setor agropecuário individualmente representou $5 \%$ do PIB nacional (CEPEA, 2020).

A expansão do agronegócio no país oferece oportunidades para a ampliação da participação de grupos domésticos nos diferentes segmentos das cadeias produtivas. Para isso, é importante construir estratégias para a geração de trabalho, renda e riqueza nos diferentes segmentos produtivos do agronegócio e não apenas na produção primária na fazenda (DE NEGRI, 2018). Comparado com a produção agropecuária, os segmentos de insumos à montante e de processamento à jusante da fazenda potencialmente melhor remuneram capital e trabalho dada sua maior economia de escala assim como seus maiores efeitos de encadeamento e de transbordamento (CORONEL, 2020).

Na cadeia produtiva da carne, o esforço para consolidar empresas brasileiras levou à recente iniciativa de constituição das "campeãs nacionais" (MORAIS; SAADFILHO, 2011). Este projeto incluiu créditos governamentais ofertados principalmente pelo Banco Nacional de Desenvolvimento Econômico e Social (BNDES) para a constituição de grandes empresas brasileiras com capacidade para conquistar mercados internacionais. O segmento de frigoríficos exportadores de carne foi um dos principais beneficiados pelos investimentos. Como consequência, o segmento agroindustrial da carne bovina se aproxima hoje de um oligopsônio criado a partir de aquisições de frigoríficos menores por grandes empresas (BOECHAT; PARRÉ, 2018; MOITA; GOLON, 2014). Não obstante, o mercado da carne bovina no Brasil ainda é caracterizado pela prevalência de vendas tipo spot ${ }^{1}$ (SILVEIRA et al., 2014) e pela baixa coordenação hierárquica (CALEMAN; ZYLBERSZTAJN, 2012).

O Brasil é o segundo maior produtor mundial e o maior exportador global de carne de gado (ABIEC, 2019). A cadeia produtiva da pecuária de corte movimenta $\mathrm{R} \$$ 597,2 bilhões por ano no país incluindo insumos para a produção pecuária $(\mathrm{R} \$ 66,2$ bilhões), produção em campo ( $\mathrm{R} \$ 104,1$ bilhões), indústria e frigoríficos ( $\mathrm{R} \$ 202,7$ bilhões) e varejo (R $\$ 224,2$ bilhões), o que representa 8,7\% do PIB brasileiro (ABIEC, 2019). São 10,9 milhões de toneladas de carne bovina produzidas anualmente, com 79,7\% destinados ao mercado interno e 20,3\% à exportação (STEIN; FLAMINO; MIRITZ, 2019).

Apesar da importância para o PIB e para a balança comercial, a cadeia produtiva da carne bovina sofre críticas pelo impacto ambiental causado, principalmente no desmatamento de novas fronteiras agrícolas (BARRETO et al., 2017; MAGRO et al., 2019). Os estados com maior crescimento do rebanho bovino de corte nos últimos 10 anos estão na Amazônia, com destaque para Roraima, Pará e Rondônia, com crescimento do rebanho de 60,6\%; 30,3\%; e 26\%, respectivamente (ABIEC, 2019).

\footnotetext{
${ }_{1}^{1}$ Mercado spot (ou mercado clássico) representa a transação sem qualquer tipo de arranjo contratual, na qual não há compromisso de continuidade da transação no futuro, sendo esta encerrada quando do pagamento no momento da entrega do produto.
}

Informe GEPEC, ISSN:1679-415X, Toledo, v. 25, n.1, p.220-239, jan./jun. 2021. 
Para atender demandas de mercados externos (FLORINDO et al., 2015), grandes frigoríficos do setor passaram a rastrear o ciclo completo da produção de carne em compromisso com o desmatamento zero na Amazônia (MARFRIG, 2019).

A produção de riqueza por grupos domésticos nos segmentos das cadeias produtivas à montante e à jusante da fazenda se apresenta como alternativa à estratégia de crescimento atual pela expansão da produção primária para novas fronteiras agrícolas com altos custos sociais e ambientais (MEDINA; SANTOS, 2017). Embora estudos revelem aumento da produção agropecuária pelo aumento da produtividade agrícola graças à incorporação de tecnologias (GASQUES et al., 2014), em novas fronteiras agropecuárias, o aumento na produção está em grande parte relacionado à incorporação de novas áreas de produção (RADA, 2013).

A sustentabilidade da cadeia produtiva da carne bovina é prioridade estratégica uma vez que o Brasil tem hoje mais área de pasto (162,2 milhões de ha) do que de agricultura (70,8 milhões de ha) (BARBOSA; CALEMAN, 2017). A urgência para a construção e alternativas para o modelo atual de crescimento pela expansão para novas fronteiras agrícolas foi ampliada pela ameaça recente de fundos internacionais de retirar investimentos de empresas relacionadas com desmatamento no Brasil (SPRING, 2020).

Neste trabalho, busca-se analisar a participação do capital brasileiro na cadeia produtiva da carne bovina produzida no Brasil como forma de identificar oportunidades para ações estratégicas de apoio ao desenvolvimento do agronegócio brasileiro a partir de investimentos em segmentos produtivos que melhor remuneram capital e trabalho como alternativa a investimentos na produção primária em novas fronteiras agrícolas. Assim, pretende-se contribuir para os esforços atuais de construção de estratégias para o desenvolvimento sustentável do agronegócio brasileiro a partir da análise sobre a participação dos grupos domésticos nos segmentos das cadeias produtivas estabelecidas no país. Especificamente, pretende-se:

- Estimar o market share de grupos domésticos em relação aos multinacionais nos principais segmentos da cadeia produtiva da carne que propiciem a ampliação da participação brasileira;

- Discutir a consolidação de empresas domésticas ao longo da cadeia produtiva como alternativa para o desenvolvimento sustentável em superação ao enfoque de expansão da produção primária para novas fronteiras agrícolas.

\section{REVISÃO DE LITERATURA}

O Brasil está passando por processo de desindustrialização e de crescente dependência econômica da exportação de commodities agrícolas e minerais (CORONEL, 2020). Assim como outros países em desenvolvimento, parte importante da economia brasileira hoje é especializada em indústrias baseadas em recursos naturais e de processamento simples (DI MEGLIO et al., 2018). Para reverter essa situação, há esforços de cientistas e gestores para que países em desenvolvimento se envolvam com o mundo global com base em setores econômicos mais sofisticados que melhor remunerem capital e trabalho (BRITTO; ROMERO; FREITAS, 2019).

$\mathrm{Na}$ história recente, economias em desenvolvimento diminuíram o atraso em relação às mais ricas na medida em que conseguiram alcançar níveis similares de conhecimento tecnológico e de qualificação da mão de obra, e não ao pela venda de ativos ao capital estrangeiro (PIKETY, 2014). Uma industrialização no sentido de atualizar a base produtiva para atividades de maior valor agregado e maior complexidade e sofisticação de suas estruturas produtivas e comerciais segue como um caminho promissor para o desenvolvimento do país (CARDOSO; REIS, 2018).

Informe GEPEC, ISSN:1679-415X, Toledo, v. 25, n.1, p.220-239, jan./jun. 2021. 
A abertura comercial ocorrida no Brasil durante a década de 1990 proporcionou grandes investimentos no agronegócio brasileiro, principalmente por grupos multinacionais (SAES; SILVEIRA, 2014). Contudo, essa dinâmica de estrangeirização do agronegócio não se deu de forma homogênea em todas as cadeias produtivas. Enquanto cadeias como a da soja passaram a contar com predominância de grupos multinacionais em seus segmentos agroindustriais (ESCHER; WILKINSON, 2019; MEDINA; RIBEIRO; BRASIL, 2016), cadeias como a da carne de gado tiveram mais investimentos de empresários locais e do Estado brasileiro (MOITA; GOLON, 2014).

A atual situação de um ambiente de negócios liberal e globalizado em que o país se insere, resulta na necessidade de um novo paradigma de desenvolvimento (BRESSER-PEREIRA; ARAÚJO; COSTA PERES, 2020). Um novo projeto de desenvolvimento pode se valer de oportunidades criadas por setores econômicos dinâmicos como é o caso do agronegócio. Um desafio crucial é a consolidação de empresas de capital doméstico ao longo das cadeias produtivas do agronegócio feito no Brasil, valendo-se inclusive de investimentos estrangeiros diretos para a dinamização econômica do país (COLEN; MAERTENS; SWINNEN, 2008).

A maior parte do esforço brasileiro para o desenvolvimento do agronegócio tem sido feito a partir de créditos de custeio subsidiados direcionados para produtores rurais em incentivo à produção de commodities agropecuárias (MAPA, 2019). Esta abordagem ainda não incorpora uma estratégia para o desenvolvimento das cadeias produtivas como um todo, incluindo não só a fazenda, mas também os segmentos de insumos à montante e os segmentos de processamento à jusante da fazenda (OSAKI; BATALHA, 2014).

A partir do estudo da cadeia produtiva da carne de gado produzida no Brasil, pretende-se explorar possibilidades para o desenvolvimento brasileiro a partir de investimentos domésticos em segmentos estratégicos das cadeias produtivas do agronegócio. Nas últimas décadas, buscando a ampliação dos benefícios do agronegócio para o país, analistas começaram a chamar atenção para a necessidade de agregação de valor aos produtos agropecuários exportados pelo Brasil (EMBRAPA, 2014; WILKINSON, 2010) e para a necessidade de alternativas de produção sustentável (STABILE et al., 2020). Este trabalho agrega aos esforços em curso ao explorar as oportunidades que a expansão do agronegócio oferece para investimentos domésticos em segmentos agroindustriais com maior remuneração e com menor impacto ambiental.

\section{METOdOLOGIA}

O primeiro passo deste trabalho foi a identificação dos principais segmentos da cadeia de produção da carne bovina no Brasil. Conforme definido pelo próprio setor produtivo, esses segmentos incluem frigoríficos, produção na fazenda, saúde animal, equipamentos, reprodução animal e sementes (ABIEC, 2019). Em seguida, foram identificadas as principais empresas operando em cada segmento produtivo, o que foi feito a partir de uma pesquisa documental dos materiais institucionais das associações setoriais e das próprias empresas.

No Brasil, as associações de produtores organizados por segmentos produtivos estimam a participação de seus associados no mercado e divulgam essas informações em anuários estatísticos, muitas vezes disponíveis em suas páginas de internet. São exemplos a Associação Brasileira das Indústrias Exportadoras de Carne (Abiec http://abiec.com.br) e outras associações citadas ao longo do trabalho. Com a lista das empresas operando em cada segmento produtivo, foi feito o levantamento dos

Informe GEPEC, ISSN:1679-415X, Toledo, v. 25, n.1, p.220-239, jan./jun. 2021. 
materiais institucionais disponíveis na página de internet de cada uma das empresas identificadas.

A partir das informações levantadas, estimou-se a participação (market share) das empresas atuando em cada segmento analisado. Para cada segmento da cadeia produtiva, identificou-se a quantidade total produzida no país (exemplo: capacidade diária de abate de animais no segmento de frigoríficos). Em seguida, foi levantada a capacidade produtiva das principais empresas atuando em cada segmento (exemplo: JBS com 34,2 mil abates diários). Em todos os casos, as fontes foram citadas ao longo do trabalho.

Adicional à estimativa do market share nos principais segmentos produtivos, foi levantada a composição acionária das empresas como forma de identificar a participação de grupos domésticos em relação aos multinacionais. Esta estimativa foi particularmente desafiadora, pois as empresas não costumam disponibilizar os dados sobre sua participação no mercado, sobretudo as multinacionais (MURPHY; BURCH; CLAPP, 2012). A participação das corporações multinacionais também é difícil de ser detectada porque muitas vezes elas vendem seus produtos com os nomes das marcas das empresas locais que foram compradas por elas (SANTOS; GLASS, 2018).

No Brasil, a composição acionária das empresas de capital aberto é protegida por lei. Não obstante, as empresas com ações na bolsa mantêm disponível em suas páginas de internet a composição acionária dos grupos controladores. Com isso, para muitos casos, foi possível identificar se o controle das empresas é feito por grupos brasileiros ou multinacionais. Os resultados são apresentados para os principais segmentos da cadeia produtiva da carne: frigoríficos, produção, saúde animal, equipamentos, nutrição animal e sementes.

Para estimar a participação de mercado total dos grupos domésticos (P) em cada segmento da cadeia produtiva, foram somadas as participações de mercado de todas as empresas com capital brasileiro $\left(\sum \mathrm{n}_{\mathrm{i}=1} \mathrm{Br}_{\mathrm{i}}\right)$. A participação doméstica na cadeia produtiva (PD) resultou da soma ponderada das participações de grupos empresariais com capital brasileiro em cada um dos seis segmentos analisados (de frigoríficos a sementes), conforme a equação 1 a seguir. A soma da participação doméstica está apresentada na tabela 4 da seção de resultados.

Em que,

$$
\mathrm{PD}=\left(\mathrm{P} 1+\mathrm{P}_{2}+\mathrm{P}_{3}+\mathrm{P}_{4}+\mathrm{P}_{5}+\mathrm{P} 6\right) / 6 \text {, sendo que } \mathrm{P}=\sum \mathrm{n}_{\mathrm{i}=1} \mathrm{Br}_{\mathrm{i}}
$$

PD - Participação doméstica na cadeia produtiva;

$\mathrm{P}$ - Participação doméstica em cada segmento (de frigoríficos a sementes)

$\sum_{\mathrm{i}=1} \mathrm{Br}_{\mathrm{i}}$ - Soma da participação doméstica de cada segmento da cadeia produtiva.

\section{RESULTADOS}

Nesta seção são apresentados os resultados da participação dos grupos domésticos nos principais segmentos da cadeia produtiva da carne: frigoríficos, produção na fazenda, saúde animal, equipamentos, reprodução animal e sementes. Ao final desta seção, o conjunto da participação doméstica na cadeia produtiva é somado de acordo com a equação 1.

Informe GEPEC, ISSN:1679-415X, Toledo, v. 25, n.1, p.220-239, jan./jun. 2021. 


\subsection{FRIGORÍFICOS}

Segundo o Ministério da Agricultura, Pecuária e Abastecimento (MAPA), são abatidos 67.058 bovinos no Brasil por dia (24.476.223 em todo o ano de 2019) (MAPA, 2020). O segmento de frigoríficos no Brasil está concentrado em três grandes empresas brasileiras de capital aberto que atuam no mercado brasileiro e internacional: JBS, Marfrig e Minerva. Apesar da concentração do mercado, há 1.334 frigoríficos cadastrados no serviço de inspeção federal no MAPA, sem considerar os que possuem inspeção estadual ou municipal (MAPA, 2020).

A JBS é uma empresa multinacional de capital aberto controlada pela brasileira J\&F Investimentos S.A. Sua composição acionária está dividida em: grupo de controle (J\&F Investimentos S.A. e Formosa) com 39,8\%; tesouraria com 2,3\%; BNDESPar com 21,3\%; e acionistas minoritários com 36,6\% (JBS, 2020). Entre os acionistas minoritários estão a Caixa Econômica Federal (CEF) com 4,9\% das ações, outros grupos brasileiros com $6,7 \%$ das ações e grupos internacionais (VALOR, 2017). Com isso, estima-se o controle de grupos brasileiros em torno de $75 \%$ (39,8\% da $\mathrm{J} \& \mathrm{~F}$ Investimentos S.A., 2,3\% da tesouraria, 21,2\% da BNDESPar, 4,9\% da CEF e 6,7\% de outros grupos).

O BNDESPar é a holding do Banco Nacional de Desenvolvimento Econômico e Social (BNDES). Com a estratégia do BNDESPar de se desfazer das ações da JBS (assim como feito com a Marfrig em 2019), a participação de grupos internacionais na empresa pode ser ampliada. O acordo de acionistas da JBS com o BNDESPar encerrou no dia 31 de dezembro de 2019.

A JBS é empresa líder no Brasil no abate de bovinos, com capacidade instalada para abater de 34,2 mil cabeças de gado por dia (JBS, 2019), o que corresponde a 51,0\% do mercado brasileiro (Tabela 1). A JBS Brasil tem atuação em 15 estados brasileiros, opera em 35 unidades de processamento de bovinos e detém as marcas Friboi, Swift, 1953 e Maturatta. Além da liderança do mercado brasileiro, a empresa tem hoje grande inserção internacional, principalmente nos Estados Unidos.

Tabela 1 - Market share dos frigoríficos que atuaram no abate, processamento e comercialização de gado no Brasil em 2019

\begin{tabular}{llllll}
\hline Empresa & $\begin{array}{l}\text { País sede } \\
\text { controlador }\end{array}$ & do & $\begin{array}{l}\text { Abate } \\
\text { (mil cabeças) }\end{array}$ & $\begin{array}{l}\text { diário } \\
\text { (\%) }\end{array}$ & $\begin{array}{l}\text { Parket } \\
\text { brasileiração (\%) }\end{array}$ \\
\hline JBS & Brasil (75\%) & 34,2 & 51,0 & 38,3 \\
Marfrig & Brasil (85\%) & 13,1 & 19,5 & 16,5 \\
Minerva & Brasil (46,8\%) & 10,9 & 16,2 & 7,6 \\
Frigol & Brasil (100\%) & 3,0 & 4,5 & 4,5 \\
Outros & Brasil & 5,9 & 8,8 & 8,8 \\
Total & & 67,1 & 100,0 & 75,7 \\
\hline
\end{tabular}

Fonte: Este trabalho.

A Marfrig, dona da marca Montana, é uma companhia brasileira de capital aberto na bolsa de valores $\mathrm{B}^{3}$ desde 2007. Seu capital social é composto apenas por ações ordinárias, todas com iguais direitos em relação à alienação do controle acionário. A composição acionária atual é de: 45,5\% de acionistas controladores; 2,2\% em ações de tesouraria; e 52,3\% em outros acionistas que incluem os bancos JP Morgan e Morgan Stanley e a empresa Brandes Investment Partners (MARFRIG, 2020). O grupo controlador é composto por MMS Participações Ltda. e seus sócios individualmente. A MMS Participações Ltda. é controlada por Marcos Antônio Molina dos Santos e Marcia Aparecida dos Santos, cada um com 50\% de participação (MARFRIG, 2020). 
Em 2019, a BNDESPar vendeu a fatia de 33,7\% que detinha do frigorífico por $\mathrm{R} \$ 2$ bilhões, obtendo um resultado positivo de 800 milhões de reais considerando os investimentos iniciais feitos em 2007. À época, os controladores, que detinham 38,9\% do capital, exerceram seus direitos de integralizar as novas ações na proporção de 0,145007 ação integralizada para cada ação possuída. Assim, em 2020 a MMS Participações Ltda. passou a ter $45,5 \%$ das ações da empresa.

No início de 2020, o Banco JP Morgan, por intermédio de algumas de suas sociedades controladas, adquiriu participação equivalente a 8,7\% do total das ações de emissão da companhia. O Morgan Stanley, por meio de suas subsidiárias LLC, atingiu participação equivalente a $6,4 \%$ do total das ações (ACIONISTA, 2020). Com isso, a participação multinacional na empresa foi estimada em 15\% (8,7\% do JP Morgan e 6,4\% do Morgan Stanley) e a brasileira em 85\%.

No Brasil, a Marfrig tem capacidade de abate de 13,1 mil cabeças de bovinos por dia (MARFRIG, 2019), e um market share estimado em 19,5\% (Tabela 1). Cerca de 29,0\% da produção da companhia são destinados ao mercado doméstico e, o restante, exportados. A Marfrig passou por um redirecionamento estratégico para focar em carne bovina. Em junho de 2018, adquiriu o controle da norte-americana National Beef e se tornou a segunda maior empresa de carne bovina do mundo, atrás da JBS.

A Minerva é empresa brasileira de capital aberto com participação de grupos internacionais entre os principais proprietários. A composição de acionistas está dividida entre: Salic (UK) Limited com 25,5\%; VDQ Holding S.A. com 19,9\%; ações de tesouraria Minerva S.A com o,7\%; e outros (free float), com 54,8\% (MINERVA, 2020).

A Salic (UK) é subsidiária integral do fundo Saudi Agricultural and Livestock Investment, gestor de recursos fundado em 2012 pelo Reino da Arábia Saudita para investir em agronegócios. Já o capital social da VDQ Holdings S.A. pertence integralmente à família Vilela de Queiroz. Embora a Salic (UK) Limited detenha a maior fatia da empresa, a Minerva é presidida por membro da família Vilela de Queiroz. Outros acionistas incluem investidores como a International Finance Corporation, o braço de investimentos do Banco Mundial (com 21,3\%) e acionistas brasileiros.

Em 2019 a BRF, que já deteve 10\% do capital da Minerva Foods, deixou de ser acionista da empresa. No mesmo ano a Minerva promoveu aumento do capital privado com novos investimentos sauditas. Antes do aumento de capital privado, os sauditas detinham 21,1\% e os Vilela de Queiroz 27,8\% da empresa. Hoje, estima-se que a Minerva possua $46,8 \%$ de capital brasileiro, sendo $19,9 \%$ do grupo VDQ Holding. A estimativa está baseada no controle acionário pela multinacional Salic Limited (com 25,5\%) e do Banco Mundial e outros grupos internacionais (com 21,3\%).

Como o terceiro maior grupo frigorífico de abate de bovinos no Brasil, a Minerva Foods tem capacidade de abater 10,9 mil cabeças por dia (MINERVA, 2019), o que representa 16,2\% dos abates no país (Tabela 1). A Minerva opera 11 plantas de abate e desossa no Brasil, além de atuação no Paraguai, Uruguai, Colômbia e Argentina (MINERVA, 2019).

Entre os grupos menores, o Frigol se destaca como o quarto maior frigorífico do país, com 22\% de participação do total que é exportado pelo país. O Frigol opera quatro unidades de bovinos nos Estados de São Paulo, Goiás e Pará. A empresa esteve em recuperação judicial de 2010 a 2019, mas hoje já possui capacidade de abate de três mil cabeças de gado por dia.

A partir do levantamento sobre as principais empresas do segmento, estimouse a participação de capital brasileiro em 75,7\% (Tabela 1). Esta estimativa está baseada na soma do market share das principais empresas do segmento considerando sua composição acionária. Como exemplo, no caso da JBS, os 51\% do market share foram

Informe GEPEC, ISSN:1679-415X, Toledo, v. 25, n.1, p.220-239, jan./jun. 2021. 
estimados com base na capacidade de abate da empresa diante do volume abatido no país divulgado pelo MAPA (MAPA, 2020). Considerando que apenas $75 \%$ do capital da empresa pertencem a grupos domésticos, a participação brasileira na empresa neste segmento de mercado foi calculada em $38,3 \%$ do total ( $75 \%$ de $51 \%$ ).

\subsection{Produção}

Segundo o último Censo Agropecuário, o Brasil possui 5.073.324 estabelecimentos agropecuários e 2.554.415 estabelecimentos que criaram gado bovino de corte, representando 50,3\% do total (IBGE, 2019). Os criadores brasileiros estão organizados em torno da Associação Brasileira de Criadores (ABC) e também em associações por raça como a associação de criadores de nelore (ACNB).

A pecuária de corte é setor tradicionalmente controlado por famílias brasileiras proprietárias de fazendas (MAGRO et al., 2019; PLETSCH et al., 2019). No entanto, tem aumentado o interesse de investidores estrangeiros por terras no Brasil. Levantamento revela que 20 grupos estrangeiros detêm 2,74 milhões de hectares de terras no Brasil (GRAIN, 2016), área que equivale a 0,7\% dos 350 milhões de hectares destinados à agropecuária no país (IBGE, 2019). Como exemplo, a BrasilAgro, com capital da multinacional argentina Cresud, possui 166 mil hectares para cana, grãos e pecuária. O estadunidense George Soros controla 127 mil hectares no Brasil, por meio da Adecoagro, destinados a atividades como café, cana, grãos e pecuária (CASTILHO, 2017).

Levantamento anterior, realizado no ano de 2007, revelou que os imóveis rurais adquiridos por estrangeiros representavam $0,6 \%$ dos imóveis rurais brasileiros e 0,7\% da área total dedicada à agropecuária (HAGE; PEIXOTO; VIEIRA FILHO, 2012). A partir das informações disponíveis indicando $0,7 \%$ das terras produtivas brasileiras controladas por grupos multinacionais (GRAIN, 2016; HAGE; PEIXOTO; VIEIRA FILHO, 2012), calculou-se a participação dos criadores brasileiros em 99,3\% do total da produção de gado de corte no Brasil (100\%-0,7\%=99,3\%).

\subsection{SAÚDE ANIMAL}

O segmento de saúde animal no Brasil é controlado por quatro grupos farmacêuticos multinacionais: MSD, Zoetis, Boehringer Ingelheim e Elanco (SANTOS; GLASS, 2018). Este controle está, em grande parte, relacionado ao patenteamento de medicamentos de última tecnologia.

A MSD Saúde Animal é braço veterinário da farmacêutica estadunidense Merck que comprou, em 2017, a indústria veterinária brasileira Vallée, uma das líderes na fabricação de produtos de saúde animal no país com mais de $22 \%$ do mercado brasileiro (VALOR, 2016). A Zoetis nasceu após decisão da Pfizer Inc. de transformar sua unidade de saúde animal em uma empresa independente, a mais nova companhia líder no mercado global que disputa com a MSD a liderança do mercado brasileiro (VALOR, 2016).

A alemã Boehringer Ingelheim se consolidou no Brasil há mais de 60 anos e aumentou sua participação no mercado nacional para quase $22 \%$ com a aquisição da Merial em 2016 (GLOBORURAL, 2018). A empresa estadunidense Elanco Animal Health chegou em 2019 a um acordo para adquirir a unidade de medicamentos veterinários da alemã Bayer e passou a configurar como a quarta maior no segmento bovinos, com 13,8\% do mercado brasileiro (ISTOÉ, 2020). 
Apesar do controle multinacional, grupos domésticos possuem uma fatia importante do mercado de saúde animal, particularmente no segmento de medicamentos genéricos. Entre os grupos com capital doméstico com fatia de mercado significativa, destacam-se: Ourofino, UCBVET, Calbos, Agener União, Real H e JA (Tabela 2).

Tabela 2 - Market share dos principais grupos atuando em saúde animal no Brasil em 2019

\begin{tabular}{|c|c|c|c|}
\hline Empresa & $\begin{array}{l}\text { País sede do } \\
\text { controlador }\end{array}$ & $\begin{array}{l}\text { Market } \\
\text { share (\%) }\end{array}$ & $\begin{array}{l}\text { Participação } \\
\text { brasileira (\%) }\end{array}$ \\
\hline MSD Saúde Animal (Vallée) & EUA & 22,3 & 0 \\
\hline Zoetis & EUA & 22,1 & $\mathrm{O}$ \\
\hline Boehringer Ingelheim (Merial) & Alemanha & 21,8 & $\mathrm{O}$ \\
\hline Elanco (Bayer) & EUA & 13,8 & $\mathrm{O}$ \\
\hline Outras & Multinacionais & 3,0 & $\mathrm{O}$ \\
\hline Ouro Fino & Brasil $(83,1 \%)$ & 9,6 & 7,9 \\
\hline UCBVET & Brasil & 1,5 & 1,5 \\
\hline Calbos & Brasil & 1,2 & 1,2 \\
\hline Agener União & Brasil & 1,2 & 1,2 \\
\hline Real H & Brasil & 1,1 & 1,1 \\
\hline JA & Brasil & 1,0 & 1,0 \\
\hline Agroquima & Brasil & 0,9 & 0,9 \\
\hline Outras & Brasil & 0,5 & 0,5 \\
\hline TOTAL & & 100,0 & 15,3 \\
\hline
\end{tabular}

Fonte: SINDAN, 2019.

A Ourofino é a maior empresa de capital doméstico neste segmento. É especialista em produtos genéricos e detém 9,6\% do mercado brasileiro de saúde para animais de produção (OUROFINO, 2019). É uma empresa de capital aberto, com composição acionária dividida da seguinte forma: $56,3 \%$ dos acionistas fundadores (brasileiros), 16,9\% da General Atlantic que é uma empresa de private equity que investe em empresas em crescimento e o restante de outros grupos nacionais (OUROFINO, 2020).

A UCBVET também figura entre as 10 empresas farmacêuticas veterinárias brasileiras com maior faturamento (SINDAN, 2019). O que antes eram duas marcas distintas - a UCB (marca utilizada no mercado nacional) e a Uzinas (marca utilizada no comércio exterior), em 2014, passou a se chamar globalmente UCBVET Saúde Animal.

A Calbos é uma empresa 100\% Brasileira consolidada no mercado veterinário com participação importante no segmento de medicamentos para tratar mastite. A Agener União é a divisão veterinária da União Química Farmacêutica Nacional, empresa brasileira com mais de 80 anos de história no mercado farmacêutico. A Real H Nutrição e Saúde Animal está no mercado desde 1985 e é uma empresa brasileira, com sede em Campo Grande (MS). A JA, com mais de quinze anos 15 anos de atuação, detém 1\% do mercado nacional. A Agroquima é uma empresa regional que possui um segmento de produtos veterinários com ectoparasiticidas, endectocidas e antimicrobianos.

A participação doméstica no segmento de saúde animal no Brasil foi estimada em $15,3 \%$ do total (Tabela 2). No caso da Ourofino, dado o market share de 9,6\% (OUROFINO, 2019), a participação doméstica foi calculada em 7,9\%, considerando o fato de a empresa possuir $83,1 \%$ de participação nacional. No caso das demais empresas de capital doméstico, a participação foi estimada a partir de dados disponibilizados pelo Sindicato Nacional da Indústria de Produtos para Saúde Animal (SINDAN, 2019). 


\subsection{EQUIPAMENTOS}

Os dois principais equipamentos utilizados na pecuária de corte são o tronco de contenção (ou brete) e a balança. O tronco é fundamental para o manejo do rebanho em atividades como vacinação, colocação de brincos, marcação e outras. Muitas vezes o próprio tronco já inclui a balança, facilitando a pesagem dos animais para acompanhar a evolução do rebanho e para definir peso no momento da venda. Vale lembrar que parte importante dos criadores brasileiros, principalmente os de menor porte, ainda não utiliza esses equipamentos.

Este é um segmento com grande número de empresas e baixa concentração de mercado, principalmente por lidar com tecnologia relativamente simples e de baixo investimento inicial. Empresas brasileiras atuando neste mercado incluem Açores, Trivelato, Sagarana, Argos, Valfran, Romancini, Troncoso, Galvão, BeckHauser e Coimma. Empresa que investem mais em pesquisa, projeto e fabricação, como no caso da Açôres, possuem alianças com as maiores empresas do mundo na área de contenção, pesagens e instrumentação. No entanto, não foram identificados investimentos estrangeiros nessas empresas, levando à estimativa de $100 \%$ de participação de grupos domésticos no segmento.

\subsection{REPRODUÇÃO}

Em 2019, o mercado brasileiro consumiu 18,5 milhões de doses de sêmen, sendo que 10,9 milhões foram produzidas no Brasil e 8,8 milhões foram importadas, com a diferença exportada ou armazenada (ASBIA, 2019). As raças com aptidão de corte tiveram crescimento em número de doses coletadas, passando de 8,2 milhões em 2018 para 9,6 milhões de doses de sêmen em 2019 (ASBIA, 2019).

Com as aquisições das centrais brasileiras, as multinacionais hoje detêm a maior parte do mercado de sêmen no Brasil. Urus é o nome da nova multinacional resultante da fusão em 2017 das operações da estadunidense Cooperative Resources International (CRI), que, no Brasil, é dona da marca Genex, e da holandesa Koepon Holding, detentora da marca global canadense Alta Genetics. A Alta Genetics passou a liderar o mercado brasileiro de genética bovina com a comercialização de 5,5 milhões de doses de sêmen em 2019 (40\% importados), o que equivale a $35 \%$ do mercado (COMPRERURAL, 2020). Como a Genex tem cerca de 15\% do mercado brasileiro, o grupo Urus concentra 50\% do mercado nacional de genética bovina (COMPRERURAL, 2020).

A CRV Lagoa faz parte do grupo CRV, cooperativa formada por fazendeiros holandeses e belgas. Maior central de genética bovina da América Latina, a CRV Lagoa oferece, desde 1971, sêmen convencional e sexado de touros nacionais e importados e controla $27 \%$ do mercado brasileiro (Tabela 3). A ABS, empresa do Grupo Genus plc, concluiu em 2018 a incorporação das operações da In Vitro Brasil e passou a controlar $8,0 \%$ do mercado mundial de genética bovina. 
Tabela 3 - Market share dos principais grupos atuando em reprodução animal no Brasil em 2019

\begin{tabular}{|c|c|c|c|}
\hline Empresa & $\begin{array}{l}\text { País sede do } \\
\text { controlador }\end{array}$ & $\begin{array}{l}\text { Market share } \\
\text { (\%) }\end{array}$ & $\begin{array}{l}\text { Participação } \\
\text { brasileira (\%) }\end{array}$ \\
\hline Alta Genetics & Canadá & 35,0 & $\mathrm{O}$ \\
\hline CRV Lagoa & Países Baixos & 27,0 & o \\
\hline Genex & EUA & 15,0 & o \\
\hline ABS (Invitro) & Reino Unido & 8,0 & o \\
\hline Outras & Multinacionais & 7,0 & o \\
\hline Outras & Brasil & 8,0 & 8,0 \\
\hline Total & & 100,0 & 8,0 \\
\hline
\end{tabular}

Fonte: Asbia (ASBIA, 2019) e páginas de internet das empresas citadas.

Mas há também grupos domésticos atuando no segmento de reprodução animal. Como exemplo, estão a Araucária Genética Bovina e a Embriotec. Muitas vezes estas empresas locais estabelecem parcerias com grandes grupos internacionais ou funcionam como seus representantes no país.

Estima-se que, enquanto os grupos multinacionais controlam 92\% do mercado de reprodução bovina, as empresas domésticas possuem $8 \%$ de market share (Tabela 3). O domínio multinacional se dá pelas quatro gigantes do segmento (Alta Genetics, CRV, Genex e ABS) e pela participação de outros grupos multinacionais estimada em $7 \%$ do mercado. As 27 empresas associadas à Associação Brasileira de Inseminação Artificial (Asbia), incluindo nacionais e multinacionais, representam juntas aproximadamente 95\% do mercado brasileiro de inseminação artificial (ASBIA, 2019).

\subsection{SEMENTES}

O mercado de sementes de pastagem no Brasil é pulverizado e com grande participação de grupos nacionais, estimada em 95\% do mercado (ANPROSEM, 2020). A Matsuda, empresa brasileira de capital fechado, é uma das maiores empresas domésticas em um grupo que inclui Gasparim, Facholi, Agrosalles, Agro Sol, Solo Pasto, Mineirão, Soesp, Wolf, Boi gordo, Germisul, Sempa, e Sementes Globo.

Entre as empresas brasileiras, existem também grupos regionais que dominam parcelas locais do mercado de sementes. Em muitos casos, são empresas familiares que têm o diferencial de estarem próximas ao produtor e, portanto, a possibilidade de fidelizar o cliente e conhecer as necessidades mais singulares da região. Exemplos de grupos regionais consolidados incluem Sementes Santa Fé, Germipasto e Agroquima.

Apesar da maior participação de grupos domésticos, há também algumas multinacionais entrando no mercado brasileiro de sementes de pastagens. Um exemplo é a Barenbrug do Brasil, uma empresa do The Royal Barenbrug Group, com sede nos Países Baixos, que começou a atuar no Brasil em 2012. Outra multinacional buscando o mercado brasileiro é a Advanta Sementes, marca do grupo indiano UPL que tem sede em Dubai.

Como não há uma tecnologia líder patenteada, este é um mercado com relativa baixa barreira de entrada e baixa concentração. Mas a disputa do mercado se faz em termos de desenvolvimento tecnológico. Há avanços na blindagem de sementes; na produção de sementes incrustradas; de sementes nucleadas e revestidas; de sementes livres de nematoides do cisto, galha e Pratylenchus; e na melhoria do grau de pureza e do valor cultural das sementes. Sementes blindadas recebem tratamento em busca de

Informe GEPEC, ISSN:1679-415X, Toledo, v. 25, n.1, p.220-239, jan./jun. 2021. 
maior resistência a intempéries. As sementes incrustadas são revestidas com fungicidas, inseticidas, organominerais e bioestimuladores que auxiliam na germinação.

A Associação Nacional de Produtores de Sementes de Gramíneas e Leguminosas Forrageiras (Anprosem) busca defender os interesses dos produtores de sementes de forrageiras e possui 33 empresas associadas. A Associação para o Fomento à Pesquisa de Melhoramento de Forrageiras (Unipasto) atua em prol da pesquisa científica para o lançamento de novas cultivares de forrageiras, possui 38 associados e mantém parceria com Embrapa.

A Embrapa tem papel importante no melhoramento de sementes de pastagem e no licenciamento de empresas para a produção dessas sementes. As cultivares liberadas pela Embrapa, na sua maioria selecionadas a partir da variabilidade natural, hoje respondem por mais de $70 \%$ do mercado brasileiro de sementes forrageiras (EMBRAPA, 2019).

\subsection{TOTAL}

Considerando o conjunto da cadeia produtiva do gado de corte no Brasil, estimou-se a participação proporcional dos grupos brasileiros em 65,6\% e, consequentemente, a participação dos grupos multinacionais em 34,4\% (Tabela 4). Esta estimativa foi feita com base no market share dos grupos domésticos nos principais segmentos produtivos analisados: frigoríficos com 75,7\% (Tabela 1); produção na fazenda com 99,3\%; saúde animal com 15,3\% (Tabela 2); equipamentos com 100\%; reprodução animal com 8\% (Tabela 3); e sementes com 95\%.

Tabela 4. Participação doméstica na cadeia produtiva da carne produzida no Brasil em 2019

\begin{tabular}{llll}
\hline Segmentos & $\begin{array}{l}\text { Nacional } \\
\text { Market share (\%) }\end{array}$ & $\begin{array}{l}\text { Multinacional } \\
\text { Market share (\%) }\end{array}$ & $\begin{array}{l}\text { Participação doméstica } \\
\text { (PD) (\%) }\end{array}$ \\
\hline Frigoríficos & 75,7 & 24,3 & 12,6 \\
Produção & 99,3 & 0,7 & 16,6 \\
Saúde animal & 15,3 & 84,7 & 2,6 \\
Equipamentos & 100,0 & 0 & 16,7 \\
Reprodução & 8,0 & 92,0 & 1,3 \\
animal & & & \\
Sementes & 95,0 & 5,0 & 15,8 \\
Total & & & 65,6 \\
\hline
\end{tabular}

Fonte: Elaboração própria.

Considerando a cadeia produtiva como um todo (o conjunto dos seis segmentos analisados), calculou-se a participação doméstica proporcional por segmento (quarta coluna da tabela 4). A participação doméstica (PD) foi estimada dividindo o market share doméstico em cada segmento pelo conjunto dos seis segmentos, conforme equação 1 apresentada na metodologia do trabalho. 


\section{CONCLUSÃO}

Objetivou-se neste trabalho identificar a participação de grupos brasileiros nos principais segmentos de produção de carne bovina no Brasil como forma de levantar oportunidades para investimentos que melhor remunerem capital e trabalho como alternativa à expansão da produção primária para novas fronteiras agrícolas. A pesquisa foi realizada com base em levantamento documental dos materiais institucionais das associações setoriais e das empresas que atuam no setor.

O levantamento revelou que $65,6 \%$ da cadeia produtiva da carne bovina produzida no Brasil são controlados por grupos brasileiros. A participação doméstica se destaca nos segmentos de frigoríficos (com 75,7\% de market share), de produção em campo (99,3\%), de equipamentos (100\%) e de sementes para pasto (95,0\%). Segmentos mais intensivos em tecnologia e em capital têm menor participação de empresas brasileiras, como são os casos de saúde animal (com 15,3\% de market share doméstico) e de reprodução animal (8,0\%).

Tanto a consolidação de grupos domésticos existentes quanto o esforço para a conquista de mercados hoje com baixa participação de empresas brasileiras podem aumentar os ganhos do Brasil com o agronegócio desenvolvido no país. A expansão dos investimentos domésticos nos segmentos agroindustriais à montante e à jusante da fazenda que melhor remuneram capital e trabalho é uma possibilidade para superar a atual estratégia de crescimento a partir de investimentos na produção primária em novas fronteiras agrícolas com altos custos sociais e ambientais (MEDINA; SANTOS, 2017).

O atual ambiente de negócios liberal e globalizado em que o Brasil está inserido resulta na necessidade de uma nova abordagem de desenvolvimento (BRESSERPEREIRA; ARAÚJO; COSTA PERES, 2020) baseada nas oportunidades criadas por setores econômicos dinâmicos como o agronegócio. A expansão do agronegócio oferece oportunidades para investimentos domésticos em segmentos de insumos produtivos e de processamento e comercialização da matéria-prima produzida em campo. Para incentivar investimentos em segmentos estratégicos, políticas públicas devem incorporar estratégias para o desenvolvimento das cadeias produtivas como um todo, em superação ao atual enfoque da política agrícola brasileira em grande parte limitada a créditos de custeio para grandes produtores rurais (MAPA, 2019).

A cadeia produtiva da carne revela a possibilidade de consolidação de empresas domésticas competindo em um mercado liberal, de livre concorrência e aberto a investimentos estrangeiros (COLEN; MAERTENS; SWINNEN, 2008). O esforço para consolidar empresas brasileiras ao longo das cadeias produtivas deve tomar em conta as lições dos investimentos públicos na constituição das "campeãs nacionais" (MORAIS; SAAD-FILHO, 2011). Um aspecto importante é que a concentração no segmento agroindustrial não resulte em aumento de poder de mercado sobre produtores rurais e outros segmentos da cadeia produtiva (BOECHAT; PARRÉ, 2018).

Este trabalho agrega aos esforços buscando a ampliação dos benefícios do agronegócio para o país (EMBRAPA, 2014; STABILE et al., 2020; WILKINSON, 2010) ao revelar as oportunidades que a expansão do agronegócio oferece para investimentos domésticos em segmentos agroindustriais com maior remuneração e com menor impacto ambiental. Como desafio para trabalhos futuros está a construção de lições comparadas de diferentes cadeias produtivas do agronegócio buscando identificar circunstâncias que favorecem o desenvolvimento local a partir de setores econômicos dinâmicos. O mapeamento das oportunidades para a participação de grupos domésticos ao longo das cadeias produtivas do agronegócio oferecerá uma compreensão ampliada das possibilidades de arranjos de mercado que favoreçam o

Informe GEPEC, ISSN:1679-415X, Toledo, v. 25, n.1, p.220-239, jan./jun. 2021. 
empreendedorismo doméstico, com atração de investimentos estrangeiros diretos e apoio estratégico do Estado.

\section{REFERÊNCIAS}

ABIEC. Beef report: Perfil da pecuária no Brasil. [s.l.] Associação Brasileira das indústrias Exportadoras de Carnes Bovinas (ABIEC), 2019.

ACIONISTA. MARFRIG (MRFG3) - Aquisição/Alienação de Participação Acionária. Disponível em: <https://acionista.com.br/marfrig-acionistascontroladores/>.

ANPROSEM. Associação nacional dos produtores de sementes. Disponível em: <https://anprosem.com.br/site/>.

ASBIA. Asbia Index 2019. Brasília: Associação Brasileira de Inseminação Artificial (Asbia), 2019. v. 39

BARBOSA, L.; CALEMAN, S. Sustentabilidade em sistemas agroindustriais: Um estudo multicasos da carne bovina de Mato Grosso do Sul, Brasil. Organizações Rurais e Agroindustriais, v. 18, n. 4, p. 315-331, 2017.

BARRETO, P.; PEREIRA, R.; BRANDÃO, A.; BAIMA, S. Os frigoríficos vão ajudar a zerar o desmatamento da Amazônia? 1. ed. Belém: Imazon; Instituto Centro da Vida, 2017.

BOECHAT, A.; PARRÉ, J. Mercado relevante e o exercício do poder de comprador: uma análise na cadeia produtiva de carne bovina brasileira entre 2004 e 2014.

Revista Econômica do Nordeste, v. 49, n. 1, p. 117-131, 2018.

BRESSER-PEREIRA, L. C.; ARAÚJO, E. C.; COSTA PERES, S. An alternative to the middle-income trap. Structural Change and Economic Dynamics, v. 52, p. 294-312, 2020.

BRITTO, G.; ROMERO, J. P.; FREITAS, E. La gran brecha: complejidad económica y trayectorias de desarrollo del Brasil y la República de Corea. Revista de la CEPAL, v. 127, n. 217-241, 2019.

CALEMAN, S. M. DE Q.; ZYLBERSZTAJN, D. Falta de Garantias e Falhas de Coordenação: Evidências do sistema agroindustrial da carne bovina. Revista de Economia e Sociologia Rural, v. 5O, n. 2, p. 223-241, 2012.

CARDOSO, F. G.; REIS, C. F. D. B. Centre and periphery in global value chains: An interpretation based on the pioneers of development. Revista de Economia Contemporanea, v. 22, n. 3, p. 1-32, 2018.

CASTILHO, A. 20 grupos estrangeiros têm 3 milhões de ha de terras no

Brasil. Disponível em: <https://deolhonosruralistas.com.br/2017/01/09/20grupos-estrangeiros-tem-3-milhoes-de-ha-de-terras-no-brasil/ > . 
CEPEA. PIB do agronegócio - Dados de 1994 a 2019. Disponível em: <https://www.cepea.esalq.usp.br/br/pib-do-agronegocio-brasileiro.aspx>. COLEN, L.; MAERTENS, M.; SWINNEN, J. Foreign direct investment as an engine for economic growth and human development: a review of the arguments and empirical evidence. [s.l.] Leuven Centre for Global Governance Studies, 2008.

COMPRERURAL. Alta Genetics consolida-se líder em genética bovina. Disponível em: <https://www.comprerural.com/alta-genetics-consolida-se-lider-emgenetica-bovina/ $>$.

CORONEL, D. A. Processo de desindustrialização da economia brasileira e possibilidade de reversão. Revista de Economia e Agronegócio, v. 17, n. 3, p. 389-398, 2020.

DE NEGRI, F. Novos caminhos para a inovação no Brasil. 1. ed. Washington: Wilson Center, 2018.

DI MEGLIO, G.; GALLEGO, J.; MAROTO, A.; SAVONA, M. Services in Developing Economies: The Deindustrialization Debate in Perspective. Development and Change, v. 49, n. 6, p. 1495-1525, 2018.

EMBRAPA. Visão 2014-2034 : o futuro do desenvolvimento tecnológico da agricultura brasileira. [s.l: s.n.]. v. 1

EMBRAPA. Anuário Leite 2019. Brasília: Embrapa Gado de Leite, 2019.

ESCHER, F.; WILKINSON, J. The political economy of the brazil-china soy-meat complex. Revista de Economia e Sociologia Rural, v. 57, n. 4, p. 656-678, 2019.

FLORINDO, T.; MEDEIROS, G.; COSTA, J.; RUVIARO, C. Competitividade dos principais países exportadores de carne bovina no período de 2002 a 2013. Revista de Economia e Agronegócio, v. 12, n. 1, p. 71-90, 2015.

GASQUES, J.; BASTOS, E.; VALDES, C. Produtividade da agricultura: resultados para o Brasil e estados selecionados. Revista de Política Agrícola, v. XXIII, n. 3, p. 87-98, 2014.

GLOBORURAL. Boehringer aumenta em $170 \%$ vendas de produtos de saúde animal em 2017. Disponível em:

<https://revistagloborural.globo.com/Noticias/Empresas-e-

Negocios/noticia/2018/04/boehringer-aumenta-em-170-vendas-de-produtos-desaude-animal-em-2017.html>.

GRAIN. El acaparamiento de tierras en el 2016: Sigue creciendo y sigue siendo malo. [s.l.] Grain, 2016.

HAGE, F.; PEIXOTO, M.; VIEIRA FILHO, J. Aquisição de Terras por Estrangeiros no Brasil: Uma Avaliação Jurídica e Econômica. [s.l.] Núcleo de Estudos e Pesquisas do Senado, 2012. 
IBGE. Censo Agropecuário 2017 - Resultados Definitivos. Disponível em: <https://sidra.ibge.gov.br/pesquisa/censo-agropecuario/censo-agropecuario-2017>. ISTOÉ. Brasil, o melhor amigo da Elanco. Disponível em: <https://www.istoedinheiro.com.br/brasil-o-melhor-amigo-da-elanco/>.

\section{JBS. JBS S.A. - Uma Companhia Global de Alimentos: Apresentação} institucional. São Paulo: JBS S.A., 2019.

JBS. Composição acionária e societária. Disponível em: $<$ https://jbss.infoinvest.com.br/investidores-esg/governancacorporativa/composicao-acionaria-e-societaria $>$.

MAGRO, T.; SANTOS, M.; JÚNIOR, L.; SILVA, J.; OLIVEIRA, E. Produção bovina e desmatamento: Análise da distribuição espacial da atividade pecuária no estado de Rondônia. IGepec, v. 23, n. 1, p. 112-126, 2019.

MAPA. Plano agrícola e pecuário 2019/2020. Brasília: Ministério da Agricultura Pecuária e Abastecimento, 2019.

MAPA. Quantidade de abate estadual por ano/espécie. Disponível em: <http://sigsif.agricultura.gov.br/sigsif_cons/!ap_abate_estaduais_cons?p_select=SI M\&p_ano=2019\&p_id_especie $=9>$.

MARFRIG. Relatório Sustentabilidade 2019. São Paulo: Marfrig, 2019. MARFRIG. Composição acionária. Disponível em: <https://ri.marfrig.com.br/pt/governanca-corporativa/composicao-acionaria >.

MEDINA, G.; RIBEIRO, G.; BRASIL, E. Participação do capital brasileiro na cadeia produtiva da soja: lições para o futuro do agronegócio nacional. Revista de Economia e Agronegócio, v. 13, n. 1, 2016.

MEDINA, G.; SANTOS, A. Curbing enthusiasm for Brazilian agribusiness: The use of actor-specific assessments to transform sustainable development on the ground.

Applied Geography, v. 85, p. 101-112, 2017.

MINERVA. Minerva: Histórico e Perfil Corporativo. Disponível em: <http://ri.minervafoods.com/minerva2012/web/mobile/conteudo_mobile.asp?idio ma $=0 \&$ tipo $=40367 \&$ conta $=28>$.

MINERVA. Composição acionária. Disponível em: $<$ http://ri.minervafoods.com/minerva2012/web/conteudo_pt.asp?idioma=o\&conta $=28 \&$ tipo $=40373>$.

MOITA, R. M.; GOLON, L. A. Oligopsônio dos Frigoríficos: Uma Análise Empírica de Poder de Mercado. Revista de Administração Contemporânea, v. 18, n. 6, p. 772-794, 2014.

MORAIS, L.; SAAD-FILHO, A. Da economia política à política econômica: o novodesenvolvimentismo e o governo Lula. Revista de Economia Política, v. 31, n. 124, p. 507-527, 2011. 
MURPHY, S.; BURCH, D.; CLAPP, J. Cereal Secrets: The World's Largest Commodity Traders and Global Trends in Agriculture. Oxfam Research Reports, n. August, p. 1-79, 2012.

NASSIF, A.; BRESSER-PEREIRA, L. C.; FEIJO, C. The case for reindustrialisation in developing countries: towards the connection between the macroeconomic regime and the industrial policy in Brazil. Cambridge Journal of Economics, $n$. February 2017, p. 355-381, 2017.

OLIVEIRA, T. J. A. DE; RODRIGUES, W. Vulnerabilidade e o desenvolvimento das regiões do agronegócio no Brasil (2007/2017). Informe GEPEC, v. 24, n. (2), p. 232-248, 2020.

OSAKI, M.; BATALHA, M. Optimization model of agricultural production system in grain farms under risk, in Sorriso, Brazil. Agricultural Systems, v. 127, n. C, p. 178-188, 2014.

OUROFINO. Sustainability Report 2018. São Paulo: Ourofino Animal Health, 2019.

OUROFINO. Ouro Fino Saúde Animal: Composição acionária. Disponível em:

<https://ri.ourofino.com/show.aspx?idCanal=jFaOEN9UYDWUCpultSya8A==>. PIKETY, T. O capital no século XXI. Rio de Janeiro: Intrínseca, 2014.

PLETSCH, L.; CASALI, M.; BAGGIO, D.; TURCATO, J. Desenvolvimento sustentável na suinocultura e bovinocultura: a experiência das propriedades do município de Três Passos-Rs. IGepec, v. 23, n. 1, p. 51-73, 2019.

RADA, N. Assessing Brazil's Cerrado agricultural miracle: An update. Food Policy, v. 38, n. 1, p. 146-155, 2013.

SAES, M. M.; SILVEIRA, R. L. F. Novas formas de organização nas cadeias agropecuárias brasileiras: Tendências recentes. Estudos Sociedade e Agricultura, v. 22, n. 2, p. 386-407, 2014.

SANTOS, M.; GLASS, V. Atlas do Agronegócio: Fatos e números sobre as corporações que controlam o que comemos. Rio de Janeiro: Fundação Heinrich Böll, 2018.

SILVEIRA, R.; CARRER, M.; CARVALHO, T.; FOSCACHES, C.; SAES, M. Formas plurais de governança: Uma análise das transações de suprimento entre frigoríficos e pecuaristas. Revista de Economia e Sociologia Rural, v. 52, n. 4, p. 761-782, 2014.

SINDAN. Anuário da indústria de produtos para saúde animal. São Paulo: Sindicato Nacional da Indústria de Produtos para Saúde Animal, 2019.

SPRING, J. Exclusive: European investors threaten Brazil divestment over deforestation. Disponível em: <https://www.reuters.com/article/us-brazil- 
environment-divestment-exclusi/exclusive-european-investors-threaten-brazildivestment-over-deforestation-idUSKBN23Q1MU>.

STABILE, M.; GUIMARÃES, A.; SILVA, D.; RIBEIRO, V.; MACEDO, M.; COE, M.; PINTO, E.; MOUTINHO, P.; ALENCAR, A. Solving Brazil's land use puzzle: Increasing production and slowing Amazon deforestation. Land Use Policy, v. 91, n. November, p. 104362, 2020.

STEIN, I.; FLAMINO, L.; MIRITZ, L. Descrição do mercado brasileiro de carne bovina no período de 2008 a 2017. Agropampa, v. 1, n. 1, 2019.

VALOR. Com Vallée, MSD deve ser líder em saúde animal. Disponível em: <https://valor.globo.com/agronegocios/noticia/2016/07/05/com-vallee-msd-deveser-lider-em-saude-animal.ghtml $>$.

VALOR. Caixa Econômica Federal reduz participação na JBS para 4,99\%. Disponível em: <https://valor.globo.com/agronegocios/noticia/2017/o1/12/caixaeconomica-federal-reduz-participacao-na-jbs-para-499.ghtml> .

WILKINSON, J. Transformações e perspectivas dos agronegócios brasileiros.

Revista Brasileira de Zootecnia, v. 39, n. SUPPL. 1, p. 26-34, 2010.

Submetido em 29/8/202O

Aprovado em 20/12/202O

\section{Sobre o Autor:}

\section{Gabriel da Silva Medina}

Professor da Faculdade de Agronomia e Medicina Veterinária da Universidade de Brasília (UnB) a partir de julho de 2019. Pós-doutor em Políticas Ambientais pelo Imperial College London (Reino Unido) (2014) com bolsa da Capes. Doutor em Ciências Naturais pela Universidade de Freiburg (Alemanha) (2008), revalidado como doutor em Ciências Agrárias. Licenciado Pleno em Ciências Agrárias (2001) com mestrado em Agriculturas Familiares e Desenvolvimento Sustentável pela Universidade Federal do Pará (2003). Professor dos Programas de Pós-graduação em Agronegócios da UnB e da UFG. Email: gabriel.medina@unb.br 